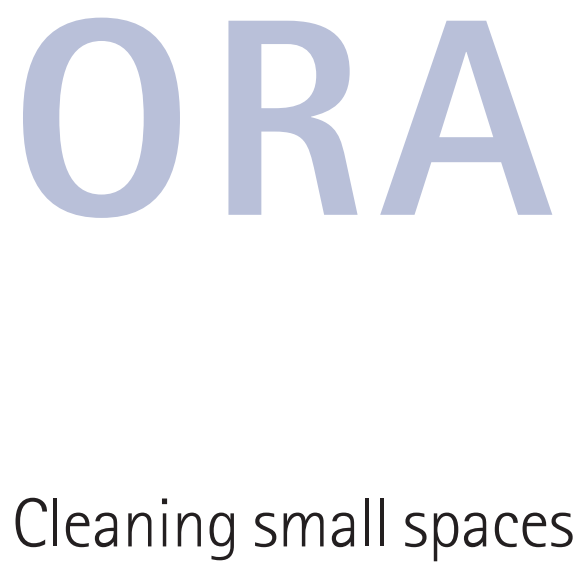

Floss and Brush from Mirage Dental, is a miniature brush designed specifically for cleaning small interdental spaces, as well as massaging the space between tooth and gum.

It can be used as an alternative for patients who find flossing the traditional way tiresome.

In addition it is particularly appropriate for patients with appliances, according to the company, as the product is built to manoeuvre around them.

It also contains $0.25 \mathrm{mg}$ of fluoride, which gradually dissolves when it comes into contact with saliva.

Reader response number 54
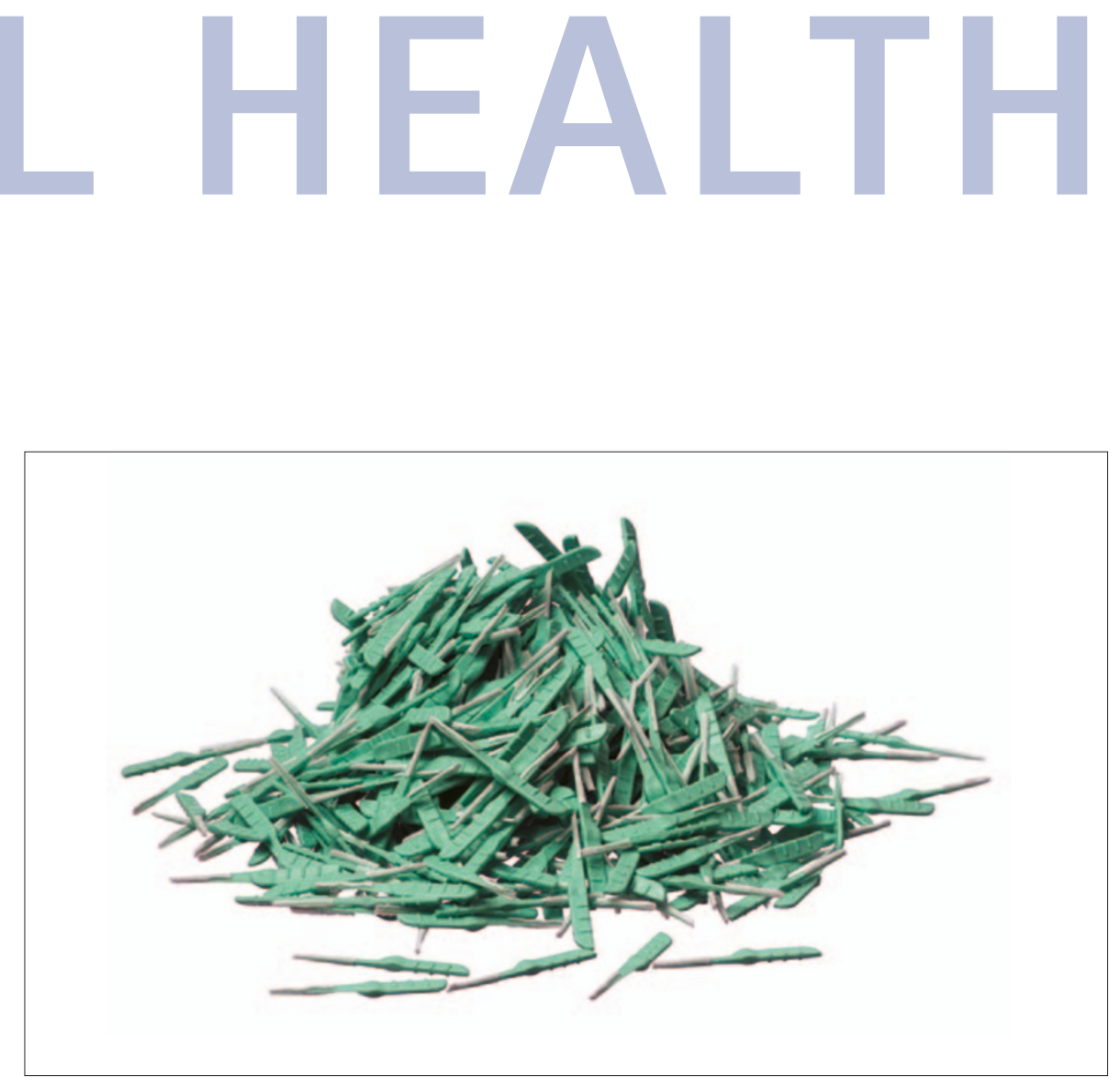


\section{Testing saliva}

GC's Saliva Testing kit is designed to test the saliva at both resting and stimulated states, as the characteristics of these forms of saliva are different, according to the company.

It can be used as a tool in assisting with early detection of the condition of the oral environment. Reader response number 55

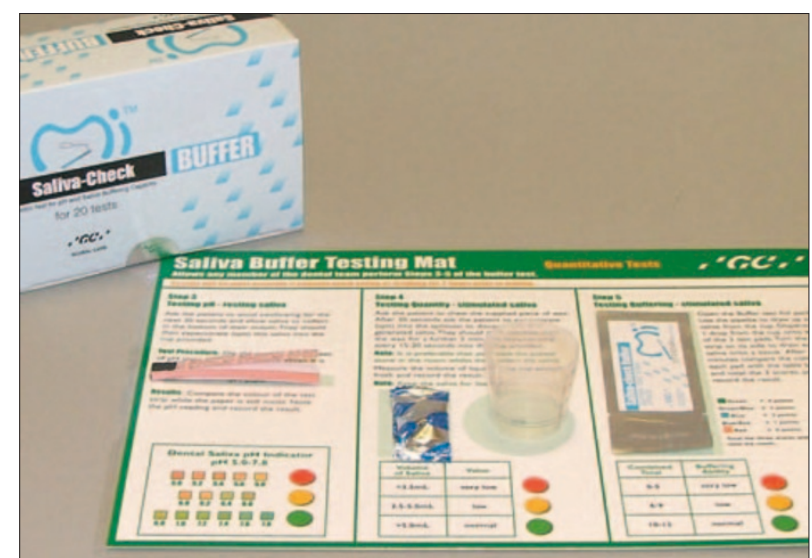

\section{Built in toothpaste}

4Square Healthcare have launched Fresh \& Go, a new toothbrush which combines a universal headed toothbrush with built in toothpaste dispenser.

With one twist Fresh \& Go dispenses one dose of mint fluoride toothpaste from inside the handle onto the bristles and contains sufficient paste for 30 applications. It is supplied with a snap-on cap and is available in red, green, blue and white.

Reader response number $\mathbf{5 7}$

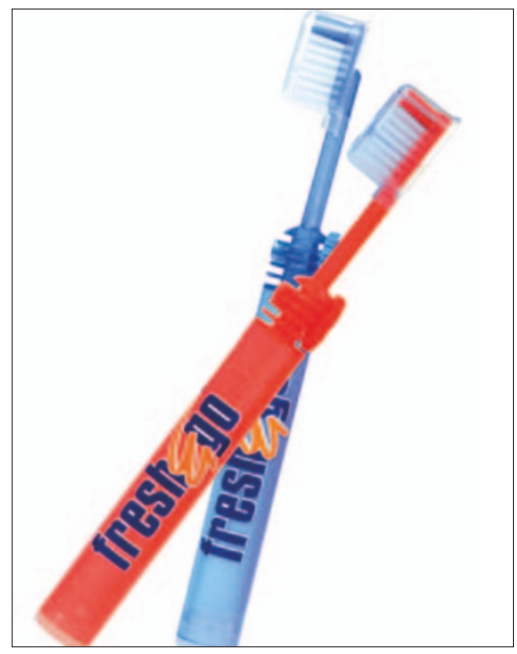

A comprehensive range of easy to use dental floss and dental tapes from leading oral health care manufacturers is available from Henry Schein.

These include GlaxoSmithKline, Colgate, Oral B, Johnson \& Johnson, Thornton, Hager \&t Werken and W.L.Gore.

Reader response number 56 


\section{Two-tone plaque discloser}

Plaqsearch is a two-tone disclosing solution from Oraldent. The two-tone action differentiates between new and old plaque. Red stains identify recent deposits and blue stains identify old deposits. It has a pleasant mint flavour and stains are easily removed by brushing, according to the company.

It is presented in a squeeze dropper bottle for easy application and comes in a $60 \mathrm{ml}$ bottle for practice use and a $15 \mathrm{ml}$ bottle for patient use.

Reader response number 58

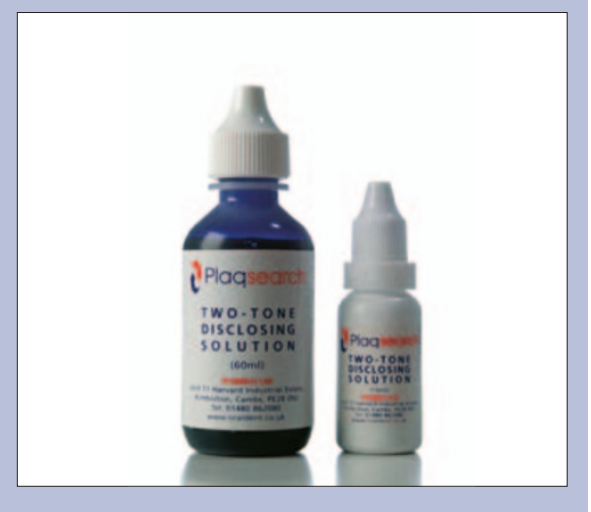

\section{Brushes for all jobs}

The Curaprox range includes CPS Prime, CPS Regular and CPS Strong and Implant brushes. CPS Prime is an ultra fine brush with a wire made of special alloyed surgical wire.

CPS Regular has a stronger wire core, denser brushes and is more resistant under heavy workloads. It is suitable for open interdental spaces following fillings, crowns and bridges.

Finally the CPS Strong and Implant brushes have a longer working length and a heavier core of plastic coated wire. They can be used for the special care needs of implants, bridges and brackets. Reader response number 59

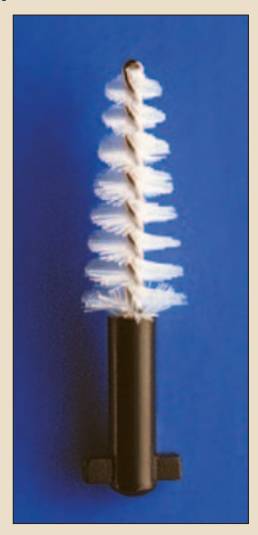

\section{Herbal solutions}

Oraldent's Natural Dentist range of herbal mouth rinses and toothpastes is available in a variety of flavours and is made from $100 \%$ natural ingredients, according to the company.

Containing echinacea, aloe vera and calendula, the Natural Dentist range provides an alternative to chlorhexidine gluconate.

The products are formulated without artificial sweeteners, alcohol, chemical preservatives or dyes.

\section{Reader response number 60}

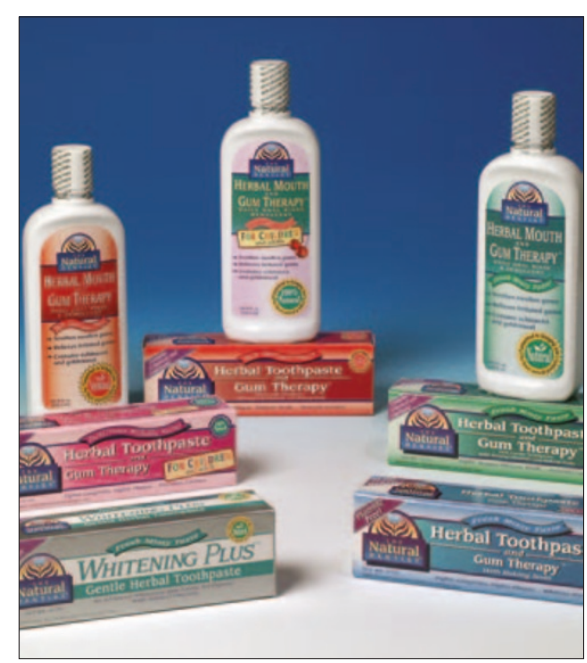

\section{Natural extracts included}

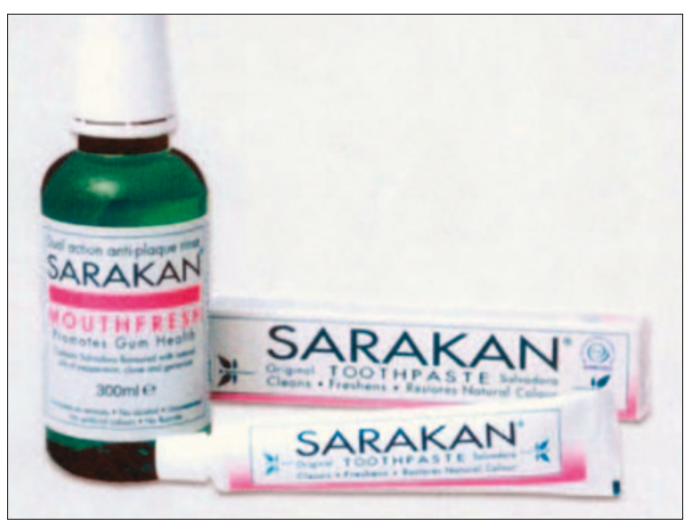

Sarakan herbal toothpaste contains extract of salavadora $\mathrm{p}$, a shrub used in the Middle East to clean teeth.

It also flavoured with extracts of oil of peppermint, clove and geranium and has no added alcohol or sugars.

It contains no artificial colours, fluoride or sodium lauryl sulphate and is suitable for adults, children and vegans.

Reader response number 61 